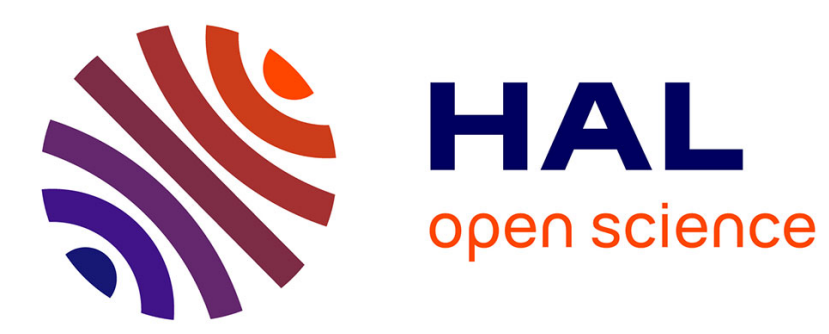

\title{
La perception de la peste en pays chrétien byzantin et musulman.
}

\author{
Marie-Hélène Congourdeau, Mohammed Melhaoui
}

\section{To cite this version:}

Marie-Hélène Congourdeau, Mohammed Melhaoui. La perception de la peste en pays chrétien byzantin et musulman.. Revue des études byzantines, 2001, 59, pp.95-124. halshs-00682286

\section{HAL Id: halshs-00682286 \\ https://shs.hal.science/halshs-00682286}

Submitted on 24 Mar 2012

HAL is a multi-disciplinary open access archive for the deposit and dissemination of scientific research documents, whether they are published or not. The documents may come from teaching and research institutions in France or abroad, or from public or private research centers.
L'archive ouverte pluridisciplinaire HAL, est destinée au dépôt et à la diffusion de documents scientifiques de niveau recherche, publiés ou non, émanant des établissements d'enseignement et de recherche français ou étrangers, des laboratoires publics ou privés. 


\title{
La perception de la peste en pays chrétien byzantin et
}

\author{
musulman \\ In: Revue des études byzantines, tome 59, 2001. pp. 95-124.
}

\section{Résumé}

REB 592001 Fiance p. 95.

Marie-Hélène Congourdeau - Mohammed Melhaoui, La perception de la peste en pays chrétien byzantin et musulman. - Le premier contact des Arabes avec la peste bubonique eut lieu lors de l'entrée du calife Omar en Palestine byzantine, en 639-640. Connue par les sources arabes sous le nom de peste d'Emmaüs, cette épidémie était une résurgence de la pandémie autrement connue sous le nom byzantin de peste de Justinien. La peste est donc dès l'abord un malheur que les musulmans partagent avec les Byzantins. Ces demiers ont historiquement de l'avance, puisqu'ils sont affrontés au fléau depuis un siècle (ses premières manifestations remontent à 540). Cependant, chacune de ces deux aires culturelles possède un certain bagage conceptuel avec lequel elle peut aborder la peste.

\section{Abstract}

The Arabs' first contact with the bubonic plague was when the caliph Omar entered Palestine in 639-640. Known to Arabic sources as the Emma us plague, the epidemic was a resurgence of the pandemia otherwise known under the Byzantine name of Justinian's plague. Thus from the very beginning the plague was a calamity the Moslems shared with the Byzantines. Even though the latter were historically in advance, since they had already been confronted to the plague for a century (its outbreak goes back to 540), each of the two cultural areas had a group of concepts which helped it deal with the plague.

Citer ce document / Cite this document :

Congourdeau Marie-Hélène, Melhaoui Mohammed. La perception de la peste en pays chrétien byzantin et musulman. In: Revue des études byzantines, tome 59, 2001. pp. 95-124.

doi : $10.3406 /$ rebyz.2001.2238

http://www.persee.fr/web/revues/home/prescript/article/rebyz_0766-5598_2001_num_59_1_2238 


\title{
LA PERCEPTION DE LA PESTE EN PAYS CHRÉTIEN BYZANTIN ET MUSULMAN ${ }^{1}$
}

\author{
Marie-Hélène CONGOURDEAU — Mohammed MELHAOUI
}

À la mémoire de M.D. Grmek († 2000)

\begin{abstract}
Summary: The Arabs' first contact with the bubonic plague was when the caliph Omar entered Palestine in 639-640. Known to Arabic sources as the Emmatus plague, the epidemic was a resurgence of the pandemia otherwise known under the Byzantine name of Justinian's plague. Thus from the very beginning the plague was a calamity the Moslems shared with the Byzantines. Even though the latter were historically in advance, since they had already been confronted to the plague for a century (its outbreak goes back to 540), each of the two cultural areas had a group of concepts which helped it deal with the plague.
\end{abstract}

Pour les Byzantins la peste bubonique, dont la peste de Justinien est la première manifestation historique, $n$ 'est pas perçue comme différente par nature des autres épidémies qui ont pu frapper le monde grec. Celle-ci est simplement plus universelle et plus mortifère. Les Byzantins utilisent donc, pour penser l'épidémie qui les frappe, les mortalités antérieures, principalement les exemples classiques de la peste de Thèbes $^{2}$ et de la peste d'Athènes ${ }^{3}$. Outre les historiens et les poètes, les philosophes grecs ont amorcé, à partir de ces épidémies, une réflexion sur la fatalité, la Providence et le destin, pour tenter de rendre compte de l'injustice qui frappe les populations aux prises avec ces mortalités ${ }^{4}$. À l'inverse, les

1. Les paragraphes sur Byzance sont de Marie-Hélène Congourdeau, les paragraphes sur l'Islam de Mohammed Melhaoui. La problématique et la rédaction finale ont été élaborées en commun.

2. SOPHOCLE, Edipe-Roi, v. 97. Cf. aussi la peste qui décima le camp des Achéens assiégeant Troie dans HoMÈRE, lliade, 1, 61 .

3. Cf. THUCYDIDE, La guerre du Péloponnèse II, 47-54. Décrivant la peste qui ravagea Constantinople en 542, Procope emprunte largement au récit de Thucydide.

4. Cf. Pseudo-ARISTOTE, Problemata, 1,7 ; Ps AleXANDRE D'APHROdisias, Problemata, c. 88 . 
Arabes, de par le climat de leur pays d'origine, ont connu peu de grandes épidémies : ils sont donc conceptuellement plus désarmés. Cependant, ils ont l'expérience d'épizooties, notamment parmi les chameaux, ce qui leur permet de concevoir une maladie qui se propage.

Au-delà de ce bagage spécifique, les deux peuples possèdent une source commune pour leur réflexion religieuse : la Bible, qui comporte au moins une grande peste, celle qui décima le camp de David après le

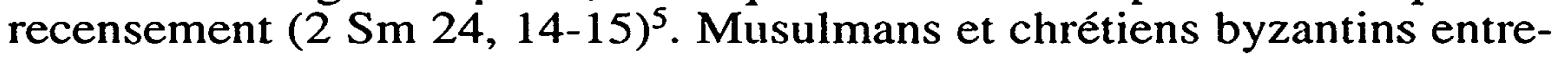
tiennent avec la Bible des rapports complexes qui présentent des analogies malgré des différences flagrantes. Les Byzantins, en tant que chrétiens, comptent les livres du Premier Testament parmi leurs Écritures canoniques (statut qui n'est plus remis en cause depuis la condamnation de Marcion au $2^{\mathrm{e}}$ s.). Mais en même temps, ces livres sacrés sont les garants d'une alliance ancienne («Ancien» Testament), reléguée au second rang par une nouvelle alliance («Nouveau» Testament), et dont la valeur est surtout typologique ou symbolique ${ }^{6}$. De leur côté, les musulmans ont accès aux données bibliques à travers le Coran qui en reprend de nombreux traits, mais expurgés car le texte reçu par les juifs et les chrétiens est considéré par Mahomet comme falsifié et donc non fiable. C'est cependant la peste de David qui servira de première référence.

Enfin, la conception que les chrétiens byzantins et les musulmans ont de Dieu (qui pour les deux traditions est le Dieu d'Abraham, c'est-à-dire un Dieu unique, transcendant mais personnel, et qui se révèle aux hommes à travers une histoire et une Ecriture) est suffisamment proche pour que les débats sur les rapports entre Dieu et la peste, et donc la perception religieuse de la peste, présentent de grandes convergences. Ce sont ces convergences qu'il nous a paru intéressant de mettre en perspective, tout en tâchant de discerner les divergences éventuelles. Nous avons (provisoirement?) écarté de la compétition deux autres «partenaires»: l'Occident médiéval et les communautés juives, qui nous semblent poser $\mathrm{d}^{\text {'autres problèmes }}{ }^{7}$.

\section{D'OÙ VIENT LA PESTE?}

La première question qui se pose, ou s'impose, est celle du «pourquoi». Le malheur fait partie de la condition humaine, mais lorsque le malheur collectif atteint des proportions extraordinaires, l'interrogation

5. Déjà dans le Pentateuque, la peste fait partie des malédictions qui s'attachent à ceux qui ne gardent pas l'Alliance : cf. Dt 28,$21 ; \mathrm{Lv} 26,25$.

6. Voir la gêne et l'ambiguïté des relations des Byzantins avec le Lévitique, dont les prescriptions, considérées comme périmées, sont cependant partiellement intégrées dans le droit canon.

7. En particulier, le rapport conflictuel entre les chrétiens d'Occident et les juifs, les premiers désignant les seconds comme responsables de la peste, sclon le réflexe du bouc émissaire, phénomène que nous n'avons rencontré ni à Byzance ni dans les pays musulmans. 
devient lancinante. Or on peut à ce niveau discerner deux grandes orientations de pensée : la première enjambe, pourrait-on dire, les causalités naturelles pour recourir directement à une causalité transcendante. La seconde, sans nier cette causalité transcendante, s'efforce de sauvegarder des causalités médianes, dans un double souci de rationalité et de disculpation de la divinité ${ }^{8}$.

\section{Confusion des plans du profane et du sacré}

La première attitude, qui ne distingue pas les plans de la nature et de la transcendance, peut prendre deux formes. Populaire, elle habille de vêtements chrétiens ou musulmans des réflexes archaïques correspondant à la fois à la «conception magique du monde» décrite par M. D. Grmek ${ }^{9}$ et à la peur atavique de tout ce que l'on ne maîtrise pas. Théologique, elle recourt à un schéma d'origine vétéro-testamentaire pour expliquer l'incompréhensible et donner une orientation à une situation qui semble sans issue : c'est le schéma péché - punition - repentir - restauration ${ }^{10}$.

\section{Permanence de mentalités païennes pré-chrétienne ou pré-islamique}

\section{* Domaine byzantin}

Lors de la peste de Justinien comme lors de la peste noire, le fléau apparaît à certains comme une irruption de l'irrationnel. Pour Procope, qui décrit la peste à Constantinople en 542, la raison humaine est désarmée car l'universalité de la pandémie défie toute explication particulière. Autant que sa cause, le sort imprévisible de chaque malade échappe à toute rationalitéll. Agathias, décrivant le retour de la peste à Constantinople en 558, énumère les explications données par les hommes du temps : certains, invoquant d'anciens oracles égyptiens et les spéculations d'astrologues perses, voient dans les malheurs présents un cycle particulièrement funeste de la course du temps; d'autres croient que c'est la colère divine qui se déchaîne contre les péchés des

8. Sur ces deux grandes orientations de pensée, nous renvoyons à M.-H. CONGOURDEAU, La société byzantine face aux grandes pandémies, dans Maladie et société à Byzance, a cura di Évelyne PATLAGEAN, Spolète 1993, p. 21-41; La maladie, la peur et la raison, Éthique. La vie en question 10, 1993/4, p. 10-27.

9. M. D. GRMEK, Les vicissitudes des notions d'infection, de contagion et de germe dans la médecine antique, dans Mémoires $V$ : Textes médicaux latins antiques, Centre Jean Palerne, Saint-Étienne 1984, p. 53-70. Cf. aussi O. TEMKIN, An historical analysis of the concept of infection, Studies in Intellectual History, Baltimore 1953.

10. Cf. D. OlSTER, Roman Defeat, Christian Response, and the Literary Construction of the Jew, Philadelphie 1994. Soulignons que, pour D. Olster, ce schéma a été adopté au $7^{*}$ siècle, au moment où les désastres de l'Empire (invasion perse avec la prise de Jérusalem, puis conquête arabe) ont conduit les Byzantins à douter de la protection divine. À son analyse, nous ajouterons que la peste de Justinien était encore présente en toile de fond, dans le désastre général.

11. PROCOPE, De bello persico, II, 22. 
hommes $^{12}$. Neuf siècles plus tard, les témoins de la grande peste de 1466 observent les mêmes réflexes chez leurs contemporains. «Les gens croient que tout advient par hasard, qu'il n'y a personne pour gouverner les événements», déclare Kritoboulos ${ }^{13}$, tandis que l'interlocuteur de Théodore Agallianos témoigne : «Certains disent que c'est le hasard qui détermine que les uns meurent et les autres non ${ }^{14}$.

Mais l'esprit grec aspire à la rationalité : même l'irrationnel doit obéir à une logique. Procope proclame ainsi que le fléau vient soit de la Destinée (non plus hasard, mais logique inaccessible à la raison humaine) soit de la Providence (logique divine) ${ }^{15}$. Et l'hagiographe de Syméon Stylite le Jeune nous montre des habitants d'Antioche, qualifiés d'impies, attribuer les pestes au mouvement des astres ${ }^{16}$.

Le reflux de la raison fait resurgir des peurs archaïques. Alors que Procope évoque les hallucinations qui font voir aux pestiférés des démons sous forme humaine ${ }^{17}$, Michel le Syrien, pour l'année 543, présente ces apparitions comme des réalités : «On voyait des spectres terrifiants dans la mer. Quand la peste passait d'un lieu à l'autre, on voyait comme une barque d'airain dans laquelle siégeaient des hommes noirs et sans tête qui parcouraient précipitamment la mer. Ils couraient en face d'Ascalon et de Gaza, et c'est par leur apparition que le fléau commença en ces lieux» ${ }^{18}$.

Le désarroi des esprits s'exprime par des blasphèmes. Le rédacteur des Miracles de saint Dèmètrios en signale un grand nombre lorsque la maladie s'abat sur Thessalonique en 586 : blasphèmes contre Dieu ${ }^{19}$ ou contre le saint qui guérit certains et pas d'autres ${ }^{20}$. Évagre le Scholastique se scandalise de voir que les enfants d'un païen sont épargnés alors que sa propre fille a succombé21. Lors d'une poussée de la peste noire à Constantinople, le patriarche Kallistos s'inquiète de la recrudescence des blasphèmes contre la Providence ${ }^{22}$.

L'antique notion de châtiment divin resurgit du fond de l'inconscient collectif grec. Châtiment collectif - selon Agathias, certains voient dans la corruption des airs, qui provoque la peste, la manifestation de la colère de la divinité, en rétribution des transgressions humaines ${ }^{23}$; - ou châti-

12. Agathias le SCHOlastiQue, Histoires, V, 10.

13. KRITOBOULOS D'IMBROS, Histoires, V, 17-18.

14. ThÉodore Agallianos (Théophane de Mèdeia), Sur la Providence, contre ceux qui pensent que s'ils fuient les lieux où soufflent les airs pestilentiels, ils seront sauvés, éd.

S. EuStRATIADÈs, Catalogue des manuscrits de Lavra, I, Paris 1925, p. 427-433.

15. PROCOPE, II, 23.

16. Vie de saint Syméon Stylite le Jeune, c. 157.

17. PROCOPE, II, 22.

18. MICHEL LE SYRIEN, Chronique, IX, 28.

19. Mir. III, 31

20. Mir. III, 41.

21. D'après la Vie de Syméon Stylite le Jeune, ch. 233.

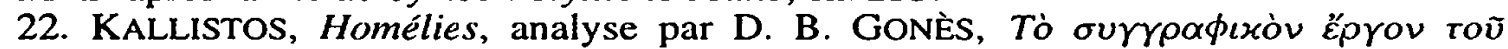

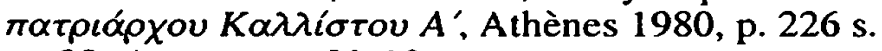

23. AGATHIAS, V, 10. 
ment individuel : d'après le médecin Stéphanos, au $7^{e} \mathrm{~s}$., les simples (oi $i \delta t \tilde{\omega} \tau \alpha \mathrm{l})$, voyant les malades, disent qu'ils sont châtiés par une puissance contraire (démoniaque) à cause d'une colère divine ${ }^{24}$. Cette divinité irascible peut être habillée de vêtements chrétiens, comme dans le texte de Jean d'Éphèse, rapporté par Michel le Syrien, qui attribue à la persécution des jacobites par l'évêque chalcédonien Domitien, en 601, la succession de fléaux qui touchent le pays : éclipse de soleil, séisme, et enfin la peste. «Par suite de tels châtiments, les Romains (Byzantins chalcédoniens) mirent fin à la persécution des orthodoxes (jacobites)» ${ }^{25}$.

\section{* Domaine islamique}

Les Arabes d'avant l'Islam, contrairement aux Grecs, n'avaient aucune expérience des pestilences humaines, du fait du climat chaud et sec de l'Arabie qui ne favorise pas la propagation d'une telle maladie ${ }^{26}$. Ils ne possédaient pas non plus, du moins dans les premiers temps, de savoir médical propre pour faire face à une épidémie. En revanche, les épizooties, qui atteignent le bétail le plus souvent, étaient bien connues en Arabie.

Le Prophète se réfère d'ailleurs à l'épizootie pour définir la peste, dans un ensemble de hadiths sur la maladie. Répondant aux questions de ses compagnons, il compare l'abcès ou le bubon à la gale qui attaque un chameau et se propage ensuite parmi le troupeau. La comparaison est importante dans la mesure où elle pose dès l'abord le problème de la propagation $^{27}$. D'autres hadiths traitent d'aspects religieux propres à la maladie, de ses causes et des moyens de s'en préserver par l'évitement de tout contact. Ces hadiths qui ont donné naissance à une matière religieuse abondante, pouvant servir à une jurisprudence sur la peste, fournissent aussi des renseignements sur les mentalités pré-islamiques. Dirigés contre la persistance de comportements païens, ils sont les sources écrites les plus complètes sur ce sujet.

C'est en particulier le cas d'un hadith qui a suscité la polémique à chaque apparition de la peste. Des théologiens intransigeants l'ont lu

24. StéPhanos D'Alexandrie, Commentaire du Promostic d'Hippocrate, I 17, éd. J. DUFFY, Corpus Medicorum Graecorum XI, 1. 2, p. 54-55.

25. MiCHEL LE SYRIEN, Chronique, X, 23.

26. L'Arabie ne constitue pas un foyer classique de la peste comme l'Éthiopie qui est à l'origine de la peste de Justinien, première pandémie du Moyen Âge.

27. Ce hadith reconnaît tacitement la transmission de certaines maladies épidémiques : «Abū Horayra - Que Dieu l'agrée - a rapporté qu'un bédouin demanda à l'Envoyé de Dieu - Que Dieu lui accorde Sa grâce et Sa paix : "Ô Envoyé de Dieu ! Comment se faitil que mes chameaux soient comme des gazelles dans le sable? Peuvent-ils être ainsi infectés quand des chameaux galeux viennent se mêler à eux ?". Il lui répondit: "Qui a contaminé le premier ?"' (AL-BUKHĀRĪ, Sommaire du Sahīh d'al-Bukhārī, Beyrouth 1987, p. 524). Al-Bukhārī (194/810 - 256/870) fut l'un des traditionnistes et compilateurs des hadiths dans un musannaf (classement) qui compte 7397 hadiths avec leurs isnād (chaînes de garants complètes). Le hadith ou tradition du Prophète devient après le Coran la deuxième source écrite du droit musulman sunnite. Cf. Encyclopédie de l'Islam, t. III, p. 24. 
comme une négation par le Prophète de la contagion. Le texte mérite une analyse approfondie, car il traite en fait de plusieurs thèmes dont le facteur commun est le rejet des croyances de l'ère de l'Ignorance (AlĞāhiliyya). Le voici, tel que rapporté par le compilateur al Bukhārī: «Abū Horayra - Que Dieu l'agrée - a rapporté que l'Envoyé de Dieu - Que Dieu lui accorde Sa grâce et Sa paix - a dit : "nulle transmission ('adwā), ni mauvais présage, ni spectre, ni 'safar', et fuyez le lépreux comme si vous fuyiez le lion" ${ }^{28}$.

Ce qui est visé, ce sont les vieux réflexes du paganisme qui avaient tendance à persister. L'Arabie d'avant l'Islam connaissait certaines pratiques issues du paganisme ("ādāt al-ğāhiliyya) ${ }^{29}$ et non conformes au message de l'unicité de Dieu, telles que l'idolâtrie, le culte des astres, la magie, des superstitions diverses. Le hadith en question ne fait que prohiber ces pratiques.

Le début du hadith, sujet de désaccord permanent, ne peut être interprété que si l'on tient compte de l'ensemble des paroles prophétiques, ainsi que du contexte et des subtilités linguistiques. C'est ce que fait le grammairien ibn Qotayba (213/829 - 276/889). Voici comment il interprète les principaux termes énumérés par le hadith : le mot 'adwā (transmission) désigne avant tout la tendance des hommes d'avant l'Islam, dès qu'il leur arrivait malheur, à en rejeter la cause sur leurs femmes, leurs habitations ou leurs montures, toutes porteuses de malheurs. Il n'y a donc pas ici un refus de la contagion au sens médical, mais un jugement rationnel, commun aux médecins et au Prophète. Ce que rejette le hadith, c'est la croyance qu'un regard de soupçon malveillant puisse provoquer (transmettre) une maladie. Les négations accumulées visent des éléments irrationnels de la mentalité pré-islamique.

Malgré la condamnation du Prophète, la conscience collective conserva cette croyance au mal provoqué par le regard fixe d'une personne ou d'un groupe, le regard qui tue. Ce n'est pas la maladie qui cause la mort, pense-t-on, c'est un soupçon malveillant. Cette croyance est connue en langage populaire arabe par l'expression al-mawt bi-l 'ayn (la mort par le regard), causée par une influence psychique mystérieuse ${ }^{30}$.

Les autres termes niés par le hadith désignent aussi des croyances superstitieuses antérieures à l'Islam : le mauvais présage (at-tiyāra) sym-

28. Ibid.

29. Cf. H-A. AL-FASSı, Al-hayāt al-iğtimā'iyya fí šamāl ġarb al-ğazīra al-'arabiyya ( $L a$ vie sociale au nord-ouest de la péninsule arabique), Riyad 1993, p. 248-289.

30. Cet aspect peut être mis en parallèle avec une conception occidentale ancienne. «Un cas particulier de la contagion indirecte est le regard: le Tractatus de epidemia de Montpellier affirme que la maladie se manifeste avec toute sa force et tue subitement lorsque le souffle (spiritus) sort des yeux des malades et se transmet aux yeux de ceux qui les entourent.» (J.-N. BIRABEN, Les hommes et la pesie en France et dans les pays européents et méditerranéens, Paris, Mouton-la Haye 1975, I, p. 22). Les mêmes cas sont observés à Avignon en 1348. Il s'agit en réalité de contagion dans le cas d'épidémie de peste pneumonique (ibid., p. 22-23). 
bolisé par un oiseau, d'où le terme atattayyur (oiseau de mauvaise augure); le spectre (al-Hāma) dont une légende arabe disait qu'un homme assassiné l'envoyait pour réclamer vengeance. Le quatrième terme (safar) désigne en réalité le deuxième mois du calendrier lunaire arabe: les Arabes de cette époque redoutaient particulièrement ce mois considéré comme portant malheur ${ }^{31}$.

Transmission par le «mauvais ceil», vengeance posthume d'un assassiné, mauvais présages, malédiction d'un temps de l'année : toutes ces croyances pré-islamiques, que veut déraciner le hadith en question, ressurgissent à la faveur de la pandémie.

\section{La colère de Dieu}

\section{* Domaine byzantin}

Après l'explication par le hasard et la Destinée, une seconde interprétation byzantine de la peste est explicitement fondée sur la Bible, et plus précisément sur une interprétation littérale des textes sacrés. La peste dans le camp de David (2 Sm 24, 14-15), mais aussi le déluge (Gn 6-7), le châtiment de Sodome (Gn 19) ou les plaies d'Égypte (Ex 7-11) offraient des épisodes bien connus pour expliquer les catastrophes par le châtiment de fautes déterminées.

Michel le Syrien adopte cette interprétation, que Dieu agisse directement (plaies d'Égypte) ${ }^{32}$, ou que, comme dans le livre de Job, il donne à Satan la permission de frapper les hommes «jusqu'à ce qu'ils méprisent toutes les choses de ce monde» ${ }^{33}$.

L'hagiographie fait de même. Pour l'auteur de la Vie de Théodore de Sykéon, une peste est envoyée par Dieu après que les Avars ont détruit le tombeau du martyr Alexandre à Drizipera ${ }^{34}$. Celui de la Vie de Syméon Stylite le Jeune fait répondre par Dieu au saint en prière lors d'une peste : «Nombreuses sont les fautes de ce peuple, pourquoi t'affliges-tu de leurs maux ?» ${ }^{35}$. Et pour celui des Miracles de saint Dèmètrios, la peste qui frappe Thessalonique en 586 «a dépassé tous les châtiments jamais envoyés par Dieu» ${ }^{36}$.

31. Soulignons enfin que la fuite devant le lépreux, dernier terme du hadith, n'exprime pas une quelconque forme de rejet social (et ne fut pas interprétée comme telle par les théologiens), mais une forte probabilité de la transmission de la maladie: ainsi le seul terme du hadith qui concerne une maladie affirme bien la contagion. Ce que confirme l'interprétation d'ibn Qotayba : les personnes saines ne doivent pas fréquenter les lépreux, car si un lépreux est trop affecté par la maladie, «son haleine forte et répugnante peut nuire à la personne et la contaminer si elle le côtoie trop longtemps ou si elle partage son repas». Une femme partageant le lit conjugal peut aussi contracter le mal, ainsi que sa descendance. Cet exemple concerne aussi les phtisiques (ibid., p. 97).

32. MICHEL LE SYRIEN, Chronique, X, 8.

33. MiCHEL LE SYRIEN, Chronique, IX, 28 : texte de Zacharie le rhéteur. Cf. Jb 1, 12.

34. Vie de Théodore de Sykéon, VII, 15.

35. Ch. 69.

36. Mir. III, 29. 
Au $15^{\text {e }}$ s., Théodore Agallianos développe une théologie de la pestechâtiment divin ${ }^{37}$. La plupart des exemples bibliques qu'il invoque pour expliquer l'épidémie qui dévaste Constantinople et sa région sont tirés du Premier Testament : le déluge (Gn 6-7), les plaies d'Égypte (Ex 7-11), les peuples barbares des visions de Daniel (Dn 11), et a contrario le repentir des habitants de Ninive qui fait renoncer Dieu à l'anéantissement de la ville (Jon 3-4). Les quelques exemples qu'il trouve dans le Nouveau Testament vont dans le même sens : le figuier frappé de stérilité par Jésus parce qu'il n'y avait pas trouvé de fruits (Mc 11, 12-14 ${ }^{38}$ ), le châtiment d'Ananie et de Saphire qui tombent morts pour avoir trompé l'Esprit saint (Ac 5, 1-11). Ces exemples bibliques le conduisent à dire : «La peste qui a fondu sur nous manifeste la colère de Dieu contre nous à cause de nos péchés. Il nous faut agir selon ces modèles anciens et Dieu aura pitié de nous». Dieu donne le bonheur aux bons et le malheur aux méchants. Puisque tout est prédéterminé par lui, fuir est non seulement inefficace mais blasphématoire : on n'échappe pas à la main de Dieu.

Sûrs d'être dans le vrai, et persuadés que toute tentative de trouver une autre explication accroîtrait la colère divine, les tenants de cette lecture «fondamentaliste» de l'Écriture ne cachent pas leur propre colère contre ceux qui invoquent des étiologies naturelles. Cette irritation contre les naturalistes ( $\left.\phi \cup \sigma(x \circ)^{\prime}\right)$ est constante, de la peste de Justinien à la peste noire, de l'auteur des Miracles de saint Dèmètrios - pour qui nul ne doit avoir l'audace de dire que l'épidémie est un phénomène naturel dû à la corruption des airs et non un châtiment divin ${ }^{39}$ - à Théodore Agallianos qui dénie à Anastase le Sinaîte le titre de didascale car il accorde de l'importance à la nature, au mouvement de l'univers et au libre-arbitre, méconnaissant ainsi la souveraineté immédiate de Dieu sur toute chose.

Qu'ils relèvent d'une mentalité archaïque ou biblique, ces auteurs ne tolèrent nulle distance entre les plans profane (la nature et ses lois) et sacré (les desseins de Dieu).

* Domaine islamique

Si la Bible est la source première des images de pestilence, le Coran en fournit aussi des images frappantes ${ }^{40}$. Mais le terme peste (T $\bar{a}^{\dagger} \bar{u} n$ ) dont l'équivalent hébreu figure dans le Premier Livre des Chroniques

37. Sur la Providence...

38. L'évangéliste précise que ce n'était pas la saison des figues, montrant par là que l'épisode réclame une lecture spirituelle et non littérale, car l'innocence du figuier rend incompréhensible l'inhabituelle sévérité de Jésus.

39. Mir. III, 33.

40. Cf. par exemple la sourate 88 al- Ġāšiya ( $L^{\prime}$ Enveloppante) ou la sourate 101 alQāri'a (Le Fléau) : ce sont des appellations métaphoriques du jugement dernier et de la résurrection. 
( 1 Ch $21,7-15$; cf. 2 Sm 24, 14-15), n'est jamais cité dans le Coran, ni sous forme de racine ni sous aucune autre forme ${ }^{4 !}$.

C'est à partir de la lecture de la peste biblique, connue à travers le filtre de la tradition du Prophète, que certains théologiens de l'Islam en vinrent à lire la peste comme un châtiment.

Le verset coranique 243 de la sourate al-Baqara (La Vache de Moïse) évoque en effet des calamités qui auraient frappé un peuple du passé : «N'as-tu pas vu ceux qui sortirent de leurs demeures - il y en avait des milliers - par crainte de la mort ? Puis Allah leur dit: "Mourez". Après quoi Il les rendit à la vie. Certes, Allah est détenteur de la faveur envers les gens; mais la plupart des gens ne sont pas reconnaissants.» (sourate II, verset 243). A la suite du rapporteur de hadiths ibn 'Abbās, ibn Hağāla et ibn Khātima au $14^{\mathrm{e}}$ s., et ibn Hağar au $15^{\mathrm{e}}$ s., virent dans ce verset une allusion à une peste qui aurait frappé le peuple d'Israël ${ }^{42}$. Selon l'auteur andalou ibn Khātima, témoin de la peste noire, les «milliers» furent au nombre de quatre mille, «ils ont été rattrapés par la mort», mais ressuscités par la suite, grâce à leur Prophète qui a imploré Dieu afin d'arrêter les ravages de cette peste ${ }^{43}$.

D'autre part, un hadith mentionne une peste qui aurait frappé par le passé une tribu d'Israël ${ }^{44}$ : «On demanda à 'Usāma ibn Zayd - que Dieu l'agrée : “qu'as-tu entendu l'Envoyé de Dieu — que Dieu lui accorde Sa grâce et Sa paix — dire au sujet de la peste ?". Il répondit: "La peste est une 'saleté' ou une 'infamie' (riğs) que Dieu avait envoyée à une catégorie du peuple d'Israël ou à ceux qui vous ont précédés. Lorsque vous

41. Dans le Dictionnaire lexique des termes du Coran (Le Caire 1991, p. 541), M.F. ABD AL-BĀKI ne mentionne que deux mots composés de la racine de ta'ana, dont le sens propre est frapper ou poignarder. Le premier cas est directement dérivé du verbe simple ta'ana (frapper) conjugué à la forme de l'accompli, à la troisième personne du masculin pluriel : ta'anū, figurant au verset 12 de la sourate At-tawba (Le Désaveu ou Le Repentir). Le deuxième cas est le nom d'action admis par le même verbe ta'ana. Il est indiqué sous la forme indéterminée - un substantif - ta'nan figurant au verset 46 de la sourate al-nisā' (Les femmes). Les deux versets ne parlent que des attaques portées contre la religion, des incriminations et des blasphèmes.

42. Cf. IBN HAĞAR, Badl al-mā 'ūn fĩ fadl al-tāeun, ms. des Archives de la Bibliothèque générale (Rabat), 312Q, f. 6. (et l'analyse de J. SUBLET, La peste prise aux rêts de la jurisprudence. Le traité d'ibn Hağar al-'Asqalānī sur la peste, Studia Islamica 33, 1971, p. 141-149); Ibn 'abī HAĞĀLA, Daf' an-niqma fī as-salāt 'alā nabī ar-rahma (Rejet du malheur dans la prière sur le Prophète de la miséricorde), Escorial 1772, f. 115-122.

43. IBN KHĀTIMA, Tahsīl garad al-qāsid fĩ tafsīl al-marad al-wāfid (Sommaire à l'attention du messager au sujet de la maladie épidémique), Escorial 1785, f. 87b. Pour la biographie de l'auteur, cf Encyclopédie de l'Islam, t. III., p. 861, s.v. Ibn Khātima. Nous ne savons pas à quelle calamité le texte coranique fait allusion. Dans un jugement absolu, puisque les images sont multiples, nous pouvons dire uniquement qu'il s'agit de la mort comme destin final de chacun et de la résurrection. C'est une leçon morale et religieuse pour les fidèles et les croyants qui doivent être persuadés de la vérité du message révélé.

44. D'après ibn 'abī Haḡāla, qui composa son traité sur la peste en 1364 au Caire, le peuple d'Israël fut touché par la peste en Égypte : «Dieu avait dit : nous leur avons envoyé la peste» (IBN 'ABī HAĞĀLA, Daf' an-niqma ..., f. 59b). 
entendez parler de son existence dans un pays, n'approchez pas de ce pays, mais si vous vous y trouvez, ne le quittez pas en la fuyant" $\gg{ }^{45}$.

Les théologiens interprétèrent le fléau du verset coranique cité plus haut (sourate II, 243) comme étant la peste, pour établir un rapport direct entre ce verset et le hadith qui évoque la peste d'Israël, et poser l'équation $:$ peste $=$ colère de Dieu = châtiment. Ibn Khātima s'inscrit contre cette interprétation. L'explication de la peste comme châtiment (riğs), selon lui, ne s'impose pas, même si l'on se rapporte au verset 134 de la sourate Al-a'rāf : «wa-lammā waqa'a alay-hum ar-riğs (et quand le châtiment les frappa)» ${ }^{46}$. La traduction exacte du terme riğs évoque la souffrance, sans aucune allusion à un châtiment d'origine divine, comme l'attestent bon nombre de théologiens musulmans. Elle est causée par une maladie, et si le terme est associé à l'histoire du peuple d'Israël, c'est que les enfants d'Israël, peuple ancien, furent les premiers frappés par une pestilence. La raison est donc d'ordre chronologique. Dans cette même argumentation, plus proche de la logique historique et philologique que de la théologie conservatrice, l'imam d'Almeria ajoute : «Les Arabes nomment chaque maladie une douleur», ce qui nous renvoie au sens propre de wağa' : le mal, la douleur et la souffrance.

Un autre hadith introduit une subtilité nouvelle. «Aicha la femme du Prophète - que Dieu lui accorde Sa grâce et $\mathrm{Sa}$ paix - a rapporté : "J'interrogeai l'Envoyé de Dieu — que Dieu lui accorde Sa grâce et Sa paix - au sujet de la peste". Il me répondit qu'elle est une agonie (adāb) que Dieu envoie à qui Il veut. Dieu en a fait une miséricorde pour les croyants. Celui qui se résigne face à la peste, sachant que rien ne l'atteint hormis ce que Dieu lui accorde, ne peut obtenir que la récompense d'un martyr» 47 .

À la notion de châtiment (pour les pécheurs), se superpose celle de miséricorde (pour le croyant musulman qui meurt de la peste) par l'accès au rang de martyr. À quelles conditions ce dernier point est-il recevable ?

Ibn Khātima rappelle qu'il faut considérer l'intégralité des paroles du Prophète qui présentent la peste comme un martyre. Le martyre au sens large est une miséricorde pour tous les croyants ${ }^{48}$, ce que confirme cet autre hadith, rapporté par le compilateur 'Anas ibn mālik : «La peste est un martyre pour chaque musulman». L'accès au rang de martyr récompense l'humble résignation face au destin tragique qui frappe le pestiféré, puisqu'il ne peut intervenir par sa faible volonté dans le destin divin qui le frappe et qu'il accepte en tant que tel, en témoin (šāhid) ${ }^{49}$ de sa propre souffrance.

45. Al-BUKHĀRī, Sommaire du sahīh al-Bukhārī, p. 360. Nous avons exposé les hadiths comme il est d'usage avec al-isnād des garants, c'est à dire les rapporteurs dignes de confiance assurant leur authenticité .

46. Sourate VII, verset 134. Il s'agit de la peste envoyée par Dieu au peuple d'Israël. Cf. dans la même sourate le verset 71. IBN KHĀTIMA, Tahsīl ..., f. 87b.

47. Ibid.

48. Ibid.

49. Ibid. f. 89a. À partir des termes šăhid et šāhīd (témoin et martyr), ibn Khătima donne trois scns au terme martyr: premièrement, l'homme qui meurt de la peste est 
Ce thème, développé au $15^{\mathrm{e}}$ siècle par ibn Hağar (qui précise que «l'attribution du martyre ne peut être destinée qu'à celui qui ne quitte pas le pays ravagé par la peste» ${ }^{50}$ ), nous renvoie au statut du martyr en Islam. Les personnes concernées, d'après le hadith d'Abì Horayra, sont : le mort par la peste, le mort-né, le mort par noyade, le mort victime d'un éboulement et le mort au combat ${ }^{51}$.

Le désir de mourir de la peste pour devenir martyr se manifesta au cours de l'épidémie d'Emmaüs, qui posa d'une manière très aiguë la question du comportement à adopter face à ses ravages, et qui fut à l'origine des premières discussions juridiques sur la calamité. À cette époque de grande piété religieuse, le compagnon du Prophète Mu'ād ibn Ğabal mourut de la peste d'Emmaüs : il avait souhaité cette façon de mourir et «Dieu exauça ses vœux», commente l'auteur du Tahsīl. Mais en réalité, les premiers croyants musulmans, compagnons du Prophète, qui souhaitaient mourir de la peste (miséricorde) à Emmaüs, se mettaient en contradiction avec les paroles du Prophète qui privilégiait la prévention et l'évitement.

\section{Distinction des plans du profane et du sacré}

\section{* Domaine byzantin}

Une autre école d'interprétation, qui sépare les plans du profane et du sacré, coexiste avec la première. Les Byzantins, sauf exception, ne renient pas l'héritage rationnel qu'ils tiennent de la Grèce antique, même s'ils le réinterprètent à la lumière des Écritures.

\section{La causalité naturelle}

Parallèlement aux explications éthico-spirituelles, les explications rationnelles classiques subsistent. Les médecins byzantins, confrontés à la peste bubonique, font appel aux schémas hérités du corpus hippocratique. Trois séries de causes expliquent la survenue d'une épidémie : la comuption des airs (qui affecte les organismes vivants par l'intermédiaire

appelé ainsi parce que les anges de la miséricorde témoignent par leur présence de sa souffrance et de la prise de son âme. Ensuite, sa présence devant Dieu, après l'épreuve douloureuse, lui vaut le titre de martyr au même titre que celui qui perd sa vie au combat au nom de Dieu. Troisièmement, le pestiféré est témoin de sa propre mort parce qu'il est conscient de sa souffrance physique et morale. C'est en fait la force morale qui surmonte la douleur et la souffrance physique, ainsi que les vertus de patience et de résignation qui font des martyrs des privilégiés.

50. IBN HAĞAR, Badl al-mā'ūn ..., ff. 47-55.

51. La liste, qui mérite des explications, est élargie à d'autres personnes, notamment la femme qui perd la vie en accomplissant son devoir conjugal, ou en accouchant. Des cas particuliers sont aussi désignés comme des martyrs, comme le mort loin de son pays, et le mort brûlé. 
des miasmes corrompus), le désordre des humeurs internes qui en résulte, et la différence des tempéraments qui prédisposent tel ou tel à être touché ou non par la maladie, à survivre ou à succomber ${ }^{52}$.

Dans son commentaire du Pronostic d'Hippocrate, le médecin Stéphanos, contemporain de la peste de Justinien, s'interroge sur l'existence de maladies infligées par les dieux et il s'appuie sur Hippocrate et Galien pour réfuter cette causalité extra-naturelle. Selon lui, la cause des pestes (les maladies le plus souvent invoquées en faveur de la causalité divine) réside dans «la constitution putréfiée de l'air qui corrompt les humeurs du corps» ${ }^{53}$.

Anastase le Sinaïte, moine du $7^{\mathrm{e}}$ siècle qui fut peut-être aussi méde$\operatorname{cin}^{54}$, adopte la même étiologie naturelle dans ses Questions et Réponses : les pestes surviennent à cause des exhalaisons putrides, de la corruption des airs, de la présence de cadavres non inhumés, surtout dans les régions insalubres ${ }^{55}$. Il n'écarte pas pour autant la causalité divine, car il arrive que Dieu utilise les causes naturelles pour corriger ( $\pi \alpha \iota \delta \varepsilon u ́ \varepsilon เ \nu)$ les hommes et les pousser au repentir.

\section{Fondement théologique des causes secondes}

Pour lire la distinction et l'articulation entre causalité naturelle et causalité divine, les Byzantins disposaient d'une réflexion théologique menée dès l'époque des Pères ${ }^{56}$. Basile de Césarée en avait affirmé les principes dans son traité Dieu n'est pas l'auteur des maux ${ }^{57}$ : les maladies surviennent à la suite de dérèglements de la nature (ainsi les pestes sont attribuées à la corruption de l'air, selon la théorie hippocratique), mais en dernière analyse c'est Dieu qui envoie ces maladies, par l'intermédiaire des causes naturelles, non pour punir les hommes mais pour prévenir des maux plus grands (maux spirituels, plus graves que les maux physiques). Les fléaux ont ainsi une fonction thérapeutique, et la métaphore médicale (en particulier l'amputation) est mise à contribution.

Anastase le Sinaïte intègre son analyse de l'étiologie des pestes dans ce schéma: Dieu certes est le créateur et le maître de tout, mais s'il a donné aux âmes le libre arbitre, il a confié aux éléments (et à ce que nous appellerions les causes secondes) le gouvernement quotidien des corps ${ }^{58}$.

52. Cf. Hippocrate, De la nature de l'homme, IX ; Péri phusôn, VI.

53. StÉPhanos, Commentaire du Pronostic...

54. Sur Anastase le Sinaite, voir un état récent de la question par J. HALDON, The works of Anastasius of Sinai : a Key source for the History of 7th century East-mediterranean Society and Belief, dans A. CAMERON and L. CONRAD eds, The byzantine and Early Islam Near-East, l : Problems in the literary source Material, Princeton 1992, p 107-147.

55. Q. $92(P G 89,732-3)$; Q. $96(P G 89,736-49)$; Q. $114(P G 89,766-68)$.

56. Pour une étude détaillée de cette réflexion, $\mathrm{cf}$. notre étude : La société byzantine...

57. $P G$ 31, 329-353. Traduction française dans Diell et le mal, Migne, Pères dans la foi 69, Paris 1997.

58. Q. 96, $P G 89,736-749$. 
Cette synthèse des deux étiologies subira une éclipse du fait d'une offensive de la causalité transcendante durant la période médio-byzantine (du fait surtout de l'hagiographie), mais elle resurgira avec la grande crise spirituelle de la fin de l'Empire. On la retrouve chez Alexios Makrembolitès au $14^{\mathrm{e}} \mathrm{s} .{ }^{59}$, et chez Marc Eugenikos au $15^{\mathrm{e}} \mathrm{s} .{ }^{60}$.

\section{* Domaine islamique}

Ibn abī Usaybi'a écrit dans l'introduction de son ouvrage intitulé Les classes de médecins: «La science des corps se trouve attachée à la science des religions» ${ }^{61}$. La dimension religieuse n'est jamais absente chez les auteurs musulmans, et ce malgré l'émergence du savoir médical d'ibn Sīnā (Avicenne), et de l'école andalouse incarnée par ibn Zuhr (Avenzoar), ibn al-Khatīb et ibn Khātima : tous admettent l'intervention de la volonté de Dieu dans la santé, la maladie et la mort. Mais, par ailleurs, la médecine arabe reste fidèle à la théorie humorale d'Hippocrate et de Galien pour expliquer les causes des maladies et des pestilences, à une différence (de taille) près : la contagiosité de la peste, qui sera développée par les médecins andalous au cours de la peste noire.

Ibn abī Hağăla, recherchant les causes de la peste, fait ainsi voisiner explications rationnelles et explications religieuses. L'apparition de la maladie a pour lui une cause d'essence «légale»: «La cause légitime de la peste est l'impudeur qui mène à la destruction de l'âge et le fait disparaître, ou de tout ce qui en sort comme la consommation des boissons enivrantes, ou la pratique de tout ce qui est illicite» ${ }^{62}$. Mais lorsqu'il s'agit d'expliquer d'où vient la peste ou comment elle se propage, ses propos sont parfois radicalement opposés, et bien loin de la cause divine. C'est ainsi que pour lui «la cause médicale de la peste réside dans la corruption de l'air qui est la matière de l'esprit» ${ }^{63}$. Cette dernière affirmation reprend fidèlement les notions d'Avicenne sur les pestilences, qui elles-mêmes dépendent étroitement d'Hippocrate.

Avicenne et les médecins andalous ont bien défini les causes naturelles de la peste. S'ils fondent leurs descriptions sur l'observation des signes cliniques apparents chez les pestiférés, leurs analyses restent fidèles à la théorie humorale d'Hippocrate ou de Galien.

59. AlEXIOS MAKREMBOLITÈS, D'où viennent la santé et la maladie?, Sabbaïticus 417 , ff. $105 \mathrm{v}-106$ : La causalité naturelle existe, mais elle cst soumise à la volonté de Dieu.

60. MARC EugÉnikos, Lettre au moine Isidore sur les bornes de la vie, PG 160, 1194-1200. Cf. notre analyse dans La peste noire à Constantinople de 1348 à 1466, Medicina nei secoli 11/2, 1999, p. 377-389: il faut penser ensemble les deux types de causalité, comme il faut tenir ensemble les vérités particulières et les vérités générales.

61. L'auteur, ophtalmologue et fils d'ophtalmologue, (né à Damas en 1270), dit qu'il trouvait sa source dans tous les Livres sacrés. Les plus grands médecins musulmans du Moyen Âge se sont aussi inspirés de la loi religieuse pour leurs idées et en faveur de l'art de guérir.

62. IBN 'ABİ IIAĞĀLA, Daf an-niqma..., f. 42a.

63. Ibid. 
Ibn Khātima définit la peste en ces termes : «C'est une fièvre maligne. Elle tient sa cause de la corruption du tempérament du cœur et de l'air de sa propre nature vers la chaleur et l'humidité. Cette fièvre est souvent mortelle, et s'accompagne d'une sensation de lassitude suivie de sueurs excessives et d'angoisse... L'épuisement apparaît le deuxième jour, la fièvre monte et les bubons sont souvent accompagnés de crachements de sang.... ${ }^{64}$. Le trait final annonce l'issue fatale de la peste pneumonique. Ces observations personnelles faites à Almeria au cours de la peste noire sont identiques à celles d'ibn al-Khatīb à Grenade.

D'autres causes, dites lointaines dans les chroniques arabes, sont présentées sommairement par les auteurs andalous. Ibn al-Khatīb évoque, pour la refuser, une causalité qui réside dans le ciel, selon les astrologues qui prétendent que des conjonctions astrales influent sur le monde. Le médecin de Grenade ne donne aucune foi à cette causalité, comme il ressort de son épître sur la maladie effrayante ${ }^{65}$.

Contrairement à son collègue et ami, ibn Khātima prend acte de ce que le rayonnement céleste hâte la corruption de l'air. Il refuse en revanche des causalités plus extrêmes et anecdotiques rapportées par ses informateurs. Ainsi, des commerçants chrétiens d'Almeria prétendaientils que la pandémie était la conséquence d'une infection provoquée par la mort des poissons flottant sur la surface des eaux des côtes turques en Orient. Foudre et tonnerre se seraient alors abattus sur la région, puis les poissons auraient été incinérés et la fumée aurait pollué l'air, emporté en d'autres endroits par le vent. Le jugement d'ibn Khātima est sans équivoque : «Cette suspicion n'est que mensonge et parole absurde» ${ }^{66}$.

Le seul facteur extérieur qu'il accepte est le dérèglement saisonnier qui peut engendrer calamités et famines, parce qu'il contrarie la chaleur et le tempérament de l'homme ${ }^{67}$. Le médecin andalou cite Hippocrate qui témoigne qu'en un seul lieu précis, à la suite d'une pluie estivale diluvienne, accompagnée d'une chaleur intense, survint une corruption

64. La grande peste de 1348-1349 était à la fois bubonique et pneumonique : «peste de couleur noire», telle était la description d'Avicenne de cette forme de peste au $! 1^{\text {te }}$ siècle dans le livre IV du Canon de la médecine, ce qui peut expliquer l'appellation peste noire. La nature de la pandémie du $14^{\mathrm{e}}$ siècle fait d'elle une peste ravageuse. Voici le témoignage d'ibn Khātima: «C'est une maladie commune à toute une population humaine et qui est souvent mortelle à cause d'un facteur répandu... Elle est différente de l'ćpizootie, qui est (une épidémie) générale propre aux bestiaux et autres animaux... Mais l'usage de 1'appellation (épizootie) appliqua le même terme aux hommes» (Tahsīl..., f. 50b-51a-b).

65. IBN AL-KIIATīB, Muqni 'at as-sā'il 'an al-marad al-hä'il (Convaincre l'interrogateur au sujet de la maladie effrayante), Escorial 1785, f. 39b. Ce manuscrit fait l'objet d'une étude et d'une traduction en cours de notre part.

66. IBN KHĀTIMA, Tahsīl, f. 53a.

67. La pollution d'origine terrestre, selon lui, peut infecter un espace déterminé. Les éléments de cette pollution peuvent être variés: la boue infecte des marécages, de l'eau stagnante et polluée de vapeur souterraines, de broussailles ou de végétation pourrie, les excréments humains ainsi que les cadavres abandonnés sur les champs de bataille, les animaux et le bétail morts d'épidémie et se trouvant en état de décomposition. Tous ces facteurs, d'après lui, peuvent putréfier l'air, l'élément simple et pur. Ibid., f. 54a. 
de l'air suivie de fièvres épidémiques très mauvaises et d'autres maladies infectieuses.

Tous les éléments invoqués comme causalité externe ne sont en réalité que des facteurs qui favorisent la propagation des épidémies : tel est aussi le facteur démographique avancé par ibn Khaldūn dans les Prolégomènes, pour expliquer les désastres qui frappent les dynasties sur leur déclin, en les rendant plus sensibles aux épidémies. Témoin de la peste noire qu'il qualifia de déluge, et des mutations politiques du $14^{\mathrm{e}}$ siècle en Occident musulman, il donne sa propre version des causes de la maladie : elle est, dit-il, la conséquence d'un État déclinant très peuplé : «Les épidémies éclatent. La raison principale est la corruption de l'atmosphère provenant d'une population surabondante... Dans les cas graves, les poumons sont atteints. On a alors des épidémies pulmonaires, ce sont les pestes, des maladies qui touchent les poumons» ${ }^{68}$.

\section{QUE FAIRE?}

\section{Doit-on fuir ?}

L'interrogation sur les causes du fléau débouche sur une interrogation plus pressante: que faire pour lui échapper? Premier réflexe: fuir. Arguments médicaux et théologiques s'affrontent pour ou contre cette réaction naturelle.

\section{Arguments médicaux : la contagion}

\section{* Domaine byzantin}

La notion de contagion (transmission d'une maladie d'un individu à un autre) s'est longtemps heurtćc au mondc scicntifique. Si la médecine populaire rapproche la maladie pestilentielle de la souillure qui se propage par contact, les médecins de la tradition hippocratique en attribuent la cause à un contexte général pathogène (air corrompu) qui touche en même temps toute une population ${ }^{69}$. Mais cette conception scientifique semble limitée à la médecine savante. Le modèle archaïque de la souillure vient spontanément à l'esprit de nombreux auteurs. Basile et Jean Chrysostome renversent les termes de la comparaison: c'est la peste qui devient la métaphore du péché qui se propage «par transmission», si bien que les hommes «se contaminent mutuellement» ${ }^{70}$. Les législateurs du Code Théodosien, voulant interdire aux chrétiens de fré-

68. V. MONTEIL (Trad.), Ibn Khaldūn, Discours sur l'histoire universelle, (alMugaddima), Beyrouth 1968, t. 2, p. 612-613.

69. Cf. HipPOCRATE, De la nature de l'homme, IX, éd. J. JouAnNA, Berlin 1975 (Corpus Medicorum Graecorum I, 1, 3); Péri phusôn, VI, éd. JONES, II, (Loeb) Cambridge MA. - Londres 1923, $1967^{2}$.

70. Basile, Sur le Psaume $1(P G 31,209)$; cf. JeAn Chr ysostome, Homélie 57 sur Jean, $P G 59$, col. 314. 
quenter les synagogues, les mettent en garde contre la contagion de l'impureté juive $^{71}$. A la fin de l'empire, Scholarios compare la peste à une malédiction qui se transmet par contact ${ }^{72}$.

Outre la permanence de l'image de la souillure, l'évidence de la contagion s'impose aux observateurs, malgré les réticences des auteurs médicaux. Historiens et simples témoins font le même constat. Durant la peste noire, en 1348, Dèmètrios Kydonès écrit à un de ses correspondants que nul n'ose inhumer même son proche parent, par crainte de la

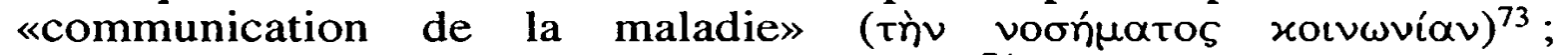
Kritoboulos fait la même observation en $1466^{74}$.

Terrorisées par la perspective de contracter la maladie, les populations fuient les lieux infectés. Mais cette attitude, qui se concevait aussi lorsque la cause de la maladie était attribuée à la corruption de l'air, a pour effet de disséminer l'épidémie, puisque les fuyards emmènent avec eux les germes de l'infection.

\section{* Domaine islamique}

Doit-on fuir? la question se posa dès la peste d'Emmaüs. Fallait-il s'isoler, pour épargner la vie des conquérants musulmans (ce que laisse entendre le sens réel des hadiths), ou conquérir la région en plein ravage épidémique et mourir de la peste pour acquérir la distinction du martyr ? Le débat, bien que religieux, occultait la question principale et épineuse, celle de la contagion, niée par les savants antiques mais affirmée par les hadiths du Prophète. À partir d'une bonne définition des symptômes de la peste, particulièrement au $14^{\mathrm{e}}$ siècle, les médecins musulmans n'eurent pas de difficultés à démontrer l'évidence de la transmission de la maladie: la médecine savante rencontrait sur ce terrain l'enseignement religieux.

Mais, redoublant la question de la contagion, une autre fut posée par les médecins andalous : s'il est établi que la maladie se transmet, pourquoi telle personne y est-elle plus vulnérable?

La réponse la plus savante fut celle d'ibn al-Khatīb. Pour lui, l'explication réside dans une interaction entre la contagiosité et la prédisposition des personnes et des lieux ${ }^{75}$. D'une part, «l'humeur personnelle s'apparente à la matière toxique, en étant prédisposée à l'admettre sans la moindre résistance... Ignorer de telles choses induit les gens en erreur

71. CODE THÉOdOSIEN XVI, 7, 3 (n ${ }^{\circ} 16$ dans A. LINDER, The Jews in Roman Imperial Legislation, Wayne State University Press, 1987) : «Eorum quoque flagitia puniantur, qui christianae religionis et nominis dignitate neglecta ludaicis semet polluere contagiis».

72. G. SCHOlARIOS, Lettre de consolation, éd. PETIT-SIDÉRIDĖS, IV, p. 298.

73. DĖmÈTRIos KYDONĖs, Lettre 21 de la classification de F. TINNEFELD (Demetrios Kydones. Briefe I, 1, I, 2 et II, Stuttgart 1981, 1982, 1991, Bibliothck der griechischen Literatur 12,16 et 33 ).

74. KRITOBOULOS, Historiae, V, 17-19, p. 204-207, éd. D. REINSCH, CFHB 22, Berlin

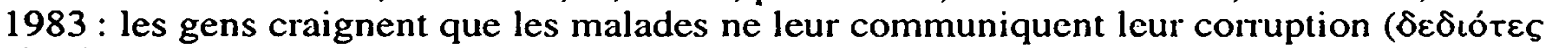
tòv фөópov).

75. IBN KHĀTIMA, Tahsīl, f. 59b-60a. 
et multiplie leur sacrifice» ${ }^{76}$. Et d'autre part, «l'existence de la contagion a été prouvée par l'expérience, la déduction, la sensation, la constatation et les fréquents témoignages» ${ }^{77}$. Ce sont là les arguments scientifiques d'une médecine savante.

Les mises en garde des médecins se heurtent à la résistance de ceux qui refusent l'idée de la contagion, soit par ignorance, soit par fatalisme religieux. «La grande masse, explique ibn al-Khatīb, n'admettant que la volonté de Dieu comme cause de la santé ou de la maladie, ignore que celle-ci réside dans la prédisposition ou la non-prédisposition ${ }^{78}$. Conscient de l'ignorance quasi générale de la société, il détaille ses arguments en faveur de la contagion : «La propagation se fait parmi ceux qui s'occupent des malades. Certains échappent à ces nuisances malgré le contact permanent qu'ils ont avec eux, d'autres y succombent bien qu'ils n'aient pas eu de contact, ou qu'ils aient eu des contacts limités dans le temps» ${ }^{79}$. C'est bien le signe que prédisposition et contagion jouent de concert. Par voie de conséquence, ceux qui croient à la contagion échappent à la mort. Parmi eux, «ceux, fort nombreux, qui ont décidé d'adopter un mode de vie ascétique, comme le mystique ibn abī Madyan dans la ville de Salé, un de ceux qui croyaient à l'existence de la contagion. Il s'est approvisionné pour une longue période, et il s'est emmuré avec sa famille, fort nombreuse. Sa ville fut décimée, et nul n'en réchappa tout au long de cette période» ${ }^{80}$.

Cet exemple concerne des personnes. Le suivant, qui concerne des lieux lointains ou isolés, rappelle la théorie d'ibn Khaldūn, selon qui il est préférable d'habiter un territoire moins peuplé et spacieux, qui ne favorise pas la circulation de l'air épidémique : «D'autres nouvelles sont relatives aux régions non touchées par la maladie, régions situées loin des routes, à l'écart des gens. Quoi de si étonnant que le cas des prisonniers musulmans sauvés par Dieu dans la maison des métiers de Séville? Ils étaient des milliers que la peste n'a pas atteints, alors qu'elle a failli décimer toute la ville. Autre exemple : Le salut des nomades arabes, en Ifriqiya (Tunisie) et ailleurs, a été assuré par l'air pur, non corrompu par la maladie» ${ }^{81}$. Il en conclut : «Parmi les fondements qu'on ne peut ignorer, il faut rappeler que la preuve d'autorité magistrale, si elle est contredite par le sens de l'observation, doit être interprétée. Dans ce cas précis, l'interprétation est celle adoptée par ceux qui ont confirmé l'existence de la contagion ${ }^{82}$.

Imprégné par les idées d'Avicenne, ibn abī Hağāla est plus précis quant à la transmission de la maladie : «Il se peut que la peste se transmette d'un malade à un bien portant par le biais de l'exhalaison d'une

76. IBN Al-KhatīB, Muqni 'at ..., f. 41b-42a.

77. Ibid., f. 42a.

78. Ibid.

79. Ibid., f. $41 \mathrm{~b}$.

80. Ibid., f. 42 b.

81. Ibid.

82. Ibid., f. 43a. 
personne contaminant une autre personne, sachant que cet élément est l'un des facteurs de la contagion» ${ }^{83}$. Et pourtant, lui aussi juge que l'organisme doit être prédisposé à contracter la maladie.

Ibn abī Hağāla avait perdu son fils, mort de la peste du Caire en 1364. Affecté par cette épreuve comme le reste de la population, croyant et résigné, il composa ce vers : «S'il n'y avait pas eu autant de larmoyants qui m'entouraient pleurant leurs frères, je me serais alors tué» ${ }^{84}$. Ce vers exprime l'état d'esprit, fait de douleur et de résignation, d'une société face aux ravages de l'épidémie.

On ne peut que s'interroger sur l'écho réel des idées de bon sens d'ibn al-Khatīb sur le terrain des comportements. Mais il fallait aussi convaincre par des preuves religieuses qu'une société conservatrice pourrait facilement comprendre.

\section{Arguments théologiques : La Providence}

La question «Doit-on fuir les lieux infectés par la peste ?» n'est pas un simple problème de santé publique. Si l'on pense que la peste est envoyée, ou permise, par Dieu, c'est aussi une question spirituelle. Fuir les lieux où Dieu a envoyé la peste ne revient-il pas à fuir la volonté de Dieu ? Une telle attitude serait au mieux inefficace; au pire il s'agit d'un péché qui peut attirer une sanction plus grave (la damnation éternelle, par exemple).

\section{* Domaine byzantin}

Dans le Pré de Jean Moschos, Procope le Scholastique se désole d'apprendre que la peste s'est déclarée à Césarée où ses deux fils sont étudiants. Il les rappellerait bien à Porphyreon, mais il craint de les exposer à la colère divine s'il cherche à les soustraire au fléau. Il consulte alors abba Zacchéios au monastère de Sainte-Sion, et le saint homme l'assure que ses fils ne mourront pas car l'épidémie va cesser ${ }^{85}$. Les scrupules de Procope nous montrent dans quel dilemme se trouvaient les Byzantins pieux confrontés aux pestes. La réponse du saint homme élude, malheureusement (pour nous), la question.

Vers la même époque, Anastase le Sinaïte est moins catégorique. À qui lui demande si la fuite est efficace dans le cas d'une épidémie, il répond que cela dépend: s'il s'agit d'un châtiment divin (cas rare mais possible), inutile de fuir. Si les causes sont naturelles, fuir vers des lieux plus salubres peut être une solution ${ }^{86}$. Cette réponse provoquera l'indignation de Théodore Agallianos, au $15^{\mathrm{e}}$ siècle, pour qui fuir la colère

83. IBN ABĪ HAĞĀLA, Daf' an-niqma..., f. 115.

84. Ibid.

85. JEAN MOSChOS, Le Pré spirituel, c. 131, PG 87, 2996.

86. ANASTASE Le Sinaïte, Question $96, P G 89,744$. 
divine est non seulement inutile mais sacrilège ${ }^{87}$; l'évêque de Mèdeia se rachète cependant aux yeux du lecteur moderne lorsqu'il offie comme alternative à la fuite le dévouement au service des malades infectés.

\section{* Domaine islamique}

Les jugements des auteurs musulmans andalous sont sévères envers ceux qui propagent de fausses idées niant la contagion : des religieux assimilés aux prophètes de malheur qui, selon ibn al-Khatīb, «ont opposé aux gens leurs épées, décidé leur destruction, même s'ils n'en avaient pas l'intention, en se limitant à la littéralité du hadith» ${ }^{88}$. Il s'agit naturellement du hadith qui est supposé nier la contagion des épidémies ${ }^{89}$.

Mais c'est dans la matière religieuse que le médecin de Grenade puise ses arguments en faveur de la contagion : «Dans la juridiction se trouvent plusieurs appuis comme le hadith "qu'aucun malade ne se désaltère avant un bien portant", et comme le dire du Compagnon (le Calife Omar au cours de la crise d'Emmaüs): "fuir le destin de Dieu vers un autre destin"».

Ibn al Khatīb va plus loin : «Il n'y a pas lieu de multiplier les commentaires à ce sujet, puisque la discussion de l'existence de la contagion d'après la juridiction ne relève pas des fonctions de cet art» ${ }^{90}$. Autrement dit, ce n'est pas à la religion de dire si la peste est contagieuse ou pas. Par ce jugement aussi rare que radical, le médecin voulait délimiter le cadre fonctionnel de chaque discipline sans les opposer, et sans aller jusqu'à la rupture. Il reste convaincu par sa foi de musulman et précise : «L'ignorance de tels arguments n'est qu'irrespect pour Dieu, et dédain pour la vie des musulmans. Certains hommes pieux ont incité les gens publiquement à revenir sur la fatwā pour la rejeter, cherchant ainsi à éviter le péril. Que Dieu nous préserve dans le dire et le faire» ${ }^{91}$. Ce texte témoigne qu'il y eut bel et bien un débat théologique intense autour d'un problème médical, celui de la contagion et du comportement qu'il fallait adopter en ces temps de malheurs.

Dans le cadre de cette polémique, ceux qui nient la contagion et les religieux intransigeants sont sévèrement jugés par les deux témoins oculaires de la pandémie à Grenade et à Almeria, qui expriment leur colère en des termes sans équivoque. Selon ibn al-Khatīb, «ne nie la contagion

87. Agallianos répond en ce sens à l'interrogateur fictif qui lui pose les questions qui, semble-t-il, étaient «dans l'air»: «Peut-on dire que ceux qui échappent à la mort en fuyant les lieux pestiférés ne sont sauvés que par la Providence? ... Est-ce un péché de fuir en temps de peste ?»: THÉODORE AGALlianos, Sur la Providence...

88. IBN AL-KHATİB, Muqni'at ..., f. 42b.

89. Rappelons la teneur de ce hadith : «Abū Horayra - que Dieu l'agrée - a rapporté que l'Envoyé de Dieu - Que Dieu lui accorde Sa Grâce et sa Paix - a dit : "nulle contagion, ni mauvais présage, ni spectre, ni 'safar', et fuyez le lépreux comme si vous fuyiez le lion"».

90. Ibid., f. 43a. Autrement dit : ce n'est pas à la juridiction de décider de l'existence de la contagion.

91. Ibid. 
que l'hypocrite qui dit le contraire de ce qu'il pense, ou l'ignorant qui n'a jamais connu d'épidémie»" ${ }^{22}$. Quant à ibn Khātima, sa qualification se résume en deux mots : «Ğahalat Guhhāl (des ignorants ignares)». Ce qui est une manière élégante pour ne pas les qualifier autrement.

\section{Prévention et traitement}

\section{Permanence de conduites archaïques}

\section{* Domaine byzantin}

La fuite, à supposer qu'elle soit efficace, n'est pas toujours possible. Il faut donc affronter le fléau. À causalité irrationnelle, remèdes irrationnels. Michel le Syrien nous a conservé le témoignage de Jean d'Éphèse sur la peste de Justinien. Celui-ci nous rapporte un certain nombre de conduites où s'exprime le désespoir des populations touchées. Ainsi, lorsqu'un homme affirme que la peste s'arrêtera si l'on jette par les fenêtres tous les récipients, aussitôt chacun s'affaire à fracasser les vases dans les ruelles, avec un résultat nul comme on peut s'en douter: Dans une ville de Palestine, certains se persuadent que l'épidémie est causée par la colère d'une idole dont le culte a été délaissé au profit du christianisme : ils retournent à l'idolâtrie première ${ }^{93}$. Au $10^{e} \mathrm{~s}$., les habitants de Sparte, avertis par Nikôn Métanoéitè que l'épidémie qui frappe leur ville est causée par la présence des juifs, expulsent la communauté juive de la ville $^{94}$. Plus pacifique, à la frontière entre superstition et spiritualité, saint Pierre d'Atroa, au $9^{\mathrm{e}} \mathrm{s}$., fait cesser une pestilence par un simple signe de croix tracé aux quatre points cardinaux ${ }^{95}$. Signe de la croix, expulsion des Juifs, affrontement de l'idolâtrie sont autant de signes de la simple christianisation de conduites archaïques.

\section{* Domaine islamique}

La lutte contre la peste est bien réelle, même si les indications restent rares et leurs significations incomplètes ${ }^{96}$. Cette lutte revêt des aspects multiples. Malgré l'arsenal religieux à caractère préventif ou médical, la société dans son ensemble, partagée entre fatalisme, pessimisme et

92. Ibid.

93. MiChel LE SYRIEN, Chronique, IX, 28.

94. Vie de Nikôn le Métanoéitè, éd. S. LAMPROS, NE 3, 1906, p. 163.

95. Vie de saint Pierre d'Atroa, éd. V. LaUrent, Subsidia Hagiographica 29, Bruxelles 1956, p. 140.

96. Une seule indication claire est mentionnée chez ibn al-Khatīb dans son manuscrit Al-wusūl li-hifd as-siha fĩ al-fusūl (Les rapprochements pour préserver la santé au cours des saisons). Parlant des changements climatiques contre nature et des facteurs pouvant infecter l'air et provoquer sa corruption, il témoigne de cette mobilisation : «Nous avons composé, quand les gens étaient en émoi au moment de la peste généraliséc, devant la porte du sultan et les médecins qui s'y retrouvaient, une épître noble, aujourd'hui répandue et connue» (IBN AL KHATīB, Al-wusūl, ms. Bibliothèque Générale de Rabat, 652d, f. 68). Les détails de la mobilisation devant les portes du palais du sultan nasride à Grenade restent à découvrir. 
troubles psychologiques devant la violence de la pandémie, s'attache plus que jamais aux remèdes irrationnels. Ce fut le temps d'un retour aux pratiques archaïques longtemps combattues par l'Islam.

L'image que les musulmans s'étaient faite de la maladie lors de la première confrontation à Emmaüs, celle d'une maladie qui ne ressemblait à aucune autre, fut déterminante: cette image resta liée à celles de la colère de Dieu, du devoir de souffrir et de la peste comme voie de martyre et miséricorde. Face à cette légitimation de la peste, différemment interprétée et répandue par les religieux, la médecine limitait sa thérapie à une prophylaxie très ancienne. Devant cette impuissance de la médecine, la religiosité populaire se réfugia dans des pratiques relevant de la superstition.

Convaincus que la peste, envoyée par Dieu, ne pouvait être ôtée que par lui, les croyants les plus modestes cherchaient à susciter sa clémence en utilisant ses paroles ${ }^{97}$.

À l'origine, se trouve la lecture du Coran considéré comme source de guérison spirituelle pour les croyants : il est ainsi recommandé de lire avec ferveur, onze fois après chaque prière obligatoire, deux sourates en particulier, Le monothéisme pur (sourate 102) et Les infidèles (sourate 109). La lecture de ces versets est considérée en théologie comme un refuge dans la parole de Dieu, et parallèlement, un appel au secours contre la peste. Trois sourates sont particulièrement recommandées en cas d'épidémie : la première sourate du Coran al-Fātiha (Le Prologue ou L'Ouverture), al-'An'ām (Les Bestiaux), et Yūnus (Jonas).

Ibn Hağar, quant à lui, recommande de réciter chez soi le verset 255 de la sourate al-Baqara (La Vache de Mö̈se ${ }^{98}$ pendant trois nuits successives. S'appuyant sur des traditions selon lesquelles le Prophète autorisait les incantations, il estime que ces pratiques ne sont pas contradictoires mais complémentaires avec les prières traditionnelles, et qu'elles peuvent agir contre la peste ${ }^{99}$.

Mais certains vont plus loin et utilisent la signification mystique des lettres pour faire de la parole sacrée un usage magique qu'ibn Khaldūn (qui le réprouve et qui ne voit en ces pratiques qu'une forme de cette magie qu'il abhorre), décrit ainsi : «Il s'agit, grâce à la magie littérale, de donner aux âmes divines le pouvoir d'agir sur la nature, à l'aide des beaux noms de Dieu et de certains mots à vertu divine, qui se composent de lettres renfermant les mystères qui se communiquent aux choses créées... La magie littérale se confond avec la magie numérique, puisqu'il y a un rapport entre les lettres et leurs valeurs numériques». Cette «science des secrets des lettres», qui constitue un phénomène social et religieux très répandu, n'est pour lui qu'«un héritage funeste du passé»,

97. M.W. Dols, The Black Death in the Middle East, Princeton N.J. 1977, p. 124.

98. Ce verset (Sourate II, verset 255) insiste sur la toute-connaissance et la toute-puissance de Dieu.

99. IBN HAĞAR, Badl al-māēū ..., f. 108. 
auquel il reconnaît une influence réelle sur les esprits mais non pas sur les maladies ${ }^{100}$.

C'est dans cette logique irrationnelle que se situe ibn Haydūr atTādilī, contemporain d'ibn Khaldūn et mathématicien réputé, qui composa un traité sur les maladies épidémiques après le passage d'une peste au Maroc en 1364. En sus de sa méthode médicale pour se préserver des maladies épidémiques, qui reproduit celle d'ibn Khātima ${ }^{101}$, il mit au point une méthode basée sur les noms de Dieu. Il avait été très frappé par des récits où ses maîtres et ses proches racontaient comment ils avaient échappé à la peste. Ainsi le rêve prémonitoire de son maître, Abū-lkāsim ibn Radwān : «Au cours d'une nuit de l'année sept cent soixantequatre (une année de peste à Fès : 1362-1363), je fus troublé par l'état de la seconde épidémie ${ }^{102}$. Je me couchai l'esprit submergé par cette histoire, et je fis un rêve dans lequel une personne venait prendre dans mes volumes un seul petit livre, et me le remettait. Il mit sa main sur la dernière ligne de la page de garde. Il me dit : voici les noms qui protègent contre l'épidémie. Alors, j'ai lu : "Ô toi le vivant, ô toi le clément, ô toi l'affectueux, ô toi le judicieux". Je m'éveillai et j'ouvris le livre. Je trouvai les mêmes paroles à la fin de chaque dernière ligne» ${ }^{103}$.

Fasciné par ce récit, ibn Haydūr at-Tādilī dressa une liste de quatre noms de Dieu : hay, halīm, hannān, hakīm. Ces quatre noms commencent tous par la lettre hà' qui fait partie des lettres ignées, censées éloigner les maladies, comme les lettres aquatiques, aériennes et terrestres ${ }^{104}$. Répétés et schématisés en diverses formes géométriques, ils étaient utilisés pour réaliser des talismans écrits sur divers supports, allant du parchemin carré ou triangulaire, en passant par le fond d'un bol, jusqu'au crâne rasé d'un patient. Ces figures magiques avaient un pouvoir bénéfique certain contre plusieurs maladies, assurait ibn Haydūr at-Tādilīs ${ }^{105}$, qui préconisait en outre d'éviter la rédaction ou la lecture des formules certains jours, comme le lundi et le samedi, afin d'éviter les influences négatives de certaines planètes ${ }^{106}$.

100. V. MONTEIL, Ibn Khaldün, Discours ..., p. 1105-1106.

101. IBN HAYDŪR, Al-amrād al-wabāiyya (Les maladies épidémiques), ms. Bibliothèque Royale, Rabat 9605. La méthode médicale que l'auteur propose est celle d'ibn Khātima. C'est le folio 71 qui est intégralement recopié.

102. Le souvenir de la grande peste de 1348-1349 est resté sans doute vivace dans l'esprit de ceux qui en avaient réchappé.

103. Ibid., f. 2.

104. Voici ce qu'écrit ibn Khaldūn sur cette magie des lettres: «Les lettres ignées éloignent les maladies froides et augmentent la chaleur souhaitéc tant au sens physique qu'astronomique, par exemple pour accroître l'influence de mars sur la guerre, le meurtre ou l'assassinat. Les lettres aquatiques servent à repousser les maladics chaudes, comme les fièvres, et à accroître les influences froides désirées, tant au sens physique qu'astronomique, par exemple, pour augmenter l'effet de la lune». Dans V. MONTEIL, Ibn Khaldūn, Discours ..., p. 1104.

105. IBN HAYDŪR, Al-amr..., f. 4.

106. Ibid., f.3. 
Sur ce point particulier des influences astrales, ibn Khaldūn porte un jugement tout aussi sévère: «Ils veulent dire que les natures supérieures et célestes se lient avec les natures inférieures, les premières étant les spiritualités astrales. C'est pourquoi les faiseurs de talismans recourent généralement à l'astrologie ... La croyance aux influences astrales détourne de la foi en Dieu et porte atteinte à l'Islam» ${ }^{107}$. Le motif de son opposition est donc religieux. Il faut comprendre que les prières et la récitation des versets du Coran ou des quatre-vingt-dix-neuf noms, dits Les plus beaux noms de Dieu, doivent être adressées à Dieu seul, par les gestes et la parole, sans intermédiaire, même si la pratique, assez courante, de transcrire un nom de Dieu, comme Le guérisseur, sous forme d'amulette ou de talismans, est tolérée.

Un autre remède utilisant des termes religieux consistait à se laver ou à absorber une boisson, préparée avec soin et piété, après avoir trempé le talisman dans le bol de la boisson, ou dans une coupe dans laquelle l'encre de l'écriture du talisman avait été dissoute. On pouvait aussi suspendre autour du cou des talismans et autres petits sachets de cuir contenant les inscriptions coraniques ${ }^{108}$.

\section{Conduites rationnelles}

À côté de ces réactions irrationnelles, d'aucuns s'efforcent de combattre le fléau en mettant en œuvre les ressources de la raison.

\section{* Domaine byzantin}

On s'attaque d'abord aux causes de la mortalité, selon les critères indiqués par les médecins : assainir l'air par de grands feux ${ }^{109}$, inhumer ou brûler les cadavres pour limiter les exhalaisons mortifères, renforcer la résistance du corps par une hygiène de vie qui garantisse l'équilibre des humeurs. Tous ces remèdes préventifs se trouvent dans les manuels médicaux. Quant aux malades déjà atteints, on les soigne avec les moyens classiques: purge, saignée, thériaque, là aussi puisés dans les manuels de thérapeutique ou iatrosophia qui comportent des chapitres sur les maladies pestilentielles ${ }^{110}$. La maladie pestilentielle étant souvent rattachée à un désordre des humeurs, les divers traitements consistent à rétablir l'équilibre interne. Les textes témoignent du dévouement général des médecins: Procope signale qu'un grand nombre succomba à Constantinople lors de la peste de $542^{111}$. Dèmètrios Kydonès est plus

107. V. MONTEIL, Ibn Khaldūn, Discours ..., p. 1098-1101.

108. M.W. DOLS, The Black Death..., p. 126.

109. L'indication remonte à Galien qui, dans son traité Ad Pisonem de theriaca, c. 16 (éd. KUHN XIV, p. 281), conseille de combattre la peste par des feux et de bonnes odeurs, se réclamant en cela d'Hippocrate.

110. Les indications des auteurs antiques, compilées par Oribase, sont reprises par Aétios d'Amida (Tétrabiblos, V, 95), Paul d'Égine, Théophane Chrysobalantès, et de là passent dans les iatrosophia.

111. Procope, De bello persico, II, 22. 
critique envers l'impuissance des médecins qui ne savent que discourir et ne sauvent personne ${ }^{112}$.

\section{* Domaine islamique}

Les médecins arabes utilisent aussi contre la peste la saignée, la purge et la thériaque. Mais ibn Khātima, qui connut la peste d'Almeria, met en doute leur efficacité contre cette maladie, si bien que pour lui la seule thérapie est la prévention, qui se traduit par des mesures prophylactiques axées sur l'hygiène ${ }^{113}$.

La saignée, à la fois préventive et curative, est l'acte médical par excellence en temps de peste. Ibn Khātima lui même la pratique largement, «aux tout premiers signes de la maladie» 114 , avant que la fièvre épidémique ne s'installe dans le corps. Car dès lors que le cœur est atteint, le pronostic est néfaste : «L'organisme ne fonctionne plus, parce que l'organisation naturelle n'est plus assurée dans son ensemble, et même les médicaments n'ont plus d'intérêt. Ils n'ont aucune chance d'être efficaces et peuvent même rajouter à la douleur et peser sur le tempérament. Dans ce cas la mort est proche» ${ }^{115}$.

Ce qui caractérise les récits du médecin d'Almeria, c'est son désarroi devant l'incapacité à soigner la maladie, même à ses débuts, parce qu'il sait qu'on ne survit pas à la peste pneumonique. Mais ce jugement ne remet pas en cause son espoir de croyant - il était imam de la mosquée d'Almeria. C'est pourquoi il n'hésite pas à pratiquer une seconde saignée sur un pestiféré, afin de soulager sa douleur. Le résultat de cette intervention l'émerveille : son patient, le seul d'un groupe de pestiférés à avoir subi cette double intervention, sera sauvé. «C'était la volonté et le destin irrésistible de Dieu, dit-il. Je n'ai rien indiqué de particulier à cet homme à la suite de la réussite de ce traitement. Ce qui s'était passé en réalité ne pouvait être que la volonté de Dieu qui donne la vie à un groupe plus qu'à un autre» ${ }^{116}$. Le miraculé fut le seul survivant d'un groupe de vingt personnes qui avaient fui la peste dès son apparition dans la campagne de Ğānā près d'Almeria.

Ibn Khātima attribue ce succès à la foi qui fait des miracles. Mais dans le cas de la peste, la foi a des limites. Ibn Zuhr (l'Avenzoar des Latins, 1072-1162) rapporte le cas d'un patient traité par la saignée et qui n'a pu être sauvé ${ }^{117}$.

112. DÈmÈTRIOS KyDONÈS, Lettres $21,50,55$ de la numérotation de F. Tinnefeld.

113. IBN KHĀTIMA, Tahsīl..., f. 65a.

114. Ibid., f. 71 a.

115. Ibid., f. 70a.

116. Ibid., f. 72 b.

117. IBN ZUHR, At-taysīr fī-l-mudāwāt wa-t-tadbīr, Rabat 1991, p. 451. 
Quant à la thériaque ${ }^{118}$, elle était depuis Galien le remède universel le plus ancien, réputé agir positivement contre la peste. D'après ibn Khātima, «Galien ... disait qu'il n'avait vu personne, ayant pris ce médicament, mourir de l'épidémie» ${ }^{119}$. Le problème est que l'épidémie soignée par Galien n'était justement pas la peste.

Le régime alimentaire accompagne la thériaque ou se conjugue avec les purges et les saignées : menus légers, jus de pomme mélangé à du citron ou eau florale mélangée à du vinaigre, soupe à la menthe, repos ... ${ }^{120}$. Dans cette prophylaxie, on déconseille la consommation du vin licite, nabīd, sans parler de l'illicite, parce qu'il chauffe le sang et augmente sa quantité, de même que les produits laitiers ${ }^{121}$.

Ibn Khaldūn, de son côté, préconise une solution liée à sa théorie sur les causes de la maladie, à savoir la surpopulation et la corruption de l'air : «Il faut absolument ménager de vastes espaces libres entre les zones peuplées, pour permettre à l'air de circuler. Ainsi est balayée la corruption, la putréfaction de l'atmosphère en contact avec les vies humaines, tandis que l'air redevient respirable. On sait que la peste est plus fréquente dans les cités surpeuplées, comme le Caire en Orient et Fès au Maroc» ${ }^{122}$. Rappelons qu'ibn Khaldūn fut témoin des ravages de la grande peste de 1348-1349 dans tout le Maghreb, et des pestes qui suivirent en 1364 au Caire et à Fès.

\section{Pastorale}

* Domaine byzantin

La thérapeutique traditionnelle ayant peu de prise sur la peste bubonique, le soin des populations passe avant tout par le soutien spirituel. C'est l'objet des homélies pour temps de peste, qui abondent au temps de la peste noire, et qui s'attachent à convertir la terreur sacrée en confiance envers le Dieu miséricordieux, tout en rendant à la liberté humaine une possibilité de se manifester par la conversion des mœurs. Grégoire Palamas, le patriarche Kallistos développent le thème de la paideia divine : le fléau n'est pas une punition (ce qui ôterait tout espoir, car la punition est tournée vers le passé qui ne peut être effacé) mais une correction (tournée vers l'avenir). Dieu corrige ses enfants bien-aimés pour les remettre dans le droit chemin et les mener au salut.

La conversion se manifeste par des actes religieux spécifiques. Procope et le rédacteur des miracles de saint Dèmètrios nous montrent les populations touchées se réfugiant spontanément dans les églises ${ }^{123}$.

118. La thériaque, dont l'invention est attribuée à Mithridate, et dont la plus fameuse recette se trouve chez Galien (De antidotis I, 7), était toujours considérée, au Moyen Âge, comme un remède universel.

119. IBN KHĀTIMA, Tahsīl..., f. 66b-67a.

120. Cf. IBN KHĀTIMA, Tahsīl..., f. $71 b$.

121. Ibid., f. 67a.

122. V. MONTEIL, Ibn Khaldūn ..., p. 614.

123. ProCoPE, De bello persico, II, 22; Mir. III, 37. Procope souligne que ni les prières ni les églises ne protègent du fléau. 
Les habitants de Thessalonique se confient à l'intercession de saint Dèmètrios, ceux d'Émèse à saint Jean-Baptiste, ceux d'Antioche au saint homme Syméon ${ }^{124}$.

La prière, l'aumône, le jeûne, les processions ${ }^{125}$, le dévouement au chevet des malades sont autant de thérapeutiques parallèles aux purges et saignées et à l'absorption de chyle de ptisane ou de terre d'Arménie.

\section{* Domaine islamique}

Les médecins musulmans, dépassés par les ravages de l'épidémie, ont tous encouragé la population à recourir aux remèdes spirituels. Mais la prévention, recommandée par la religion, passait avant le souhait de mourir de la peste dans le but d'acquérir le rang de martyr. Ibn Khātima expose un hadith très instructif. Le Prophète avait dit : «Ne souhaitez pas rencontrer l'ennemi, mais demandez à Dieu de pouvoir rester dans le bien-être» ${ }^{126}$. Ibn Hağāla, reprenant ce hadith, ajoute que le Prophète préférait la voie de la grâce, qui passe par la prévention, à celle de la souffrance par la peste ou d'autres malheurs ${ }^{127}$, même si les souffrances ont valeur de martyre pour le mort de la peste.

C'est parce que les médecins sont incapables de repousser la peste qu'ibn Hağar s'efforce de démontrer les vertus de la résignation et de la confiance en Dieu, pour atteindre la miséricorde ${ }^{128}$; la seule condition pour atteindre le but suprême du martyre est de ne pas fuir la peste, conformément au hadith du Prophète. Il suffit d'y songer, sans souhaiter mourir de la peste pour autant. Si celui qui meurt de la peste dans cet état d'esprit est considéré comme un martyr, c'est qu'un pestiféré, qui n'a pu lutter contre la douleur et la mort, faute de remède efficace sur terre, mérite un sort heureux au paradis ${ }^{129}$.

Cette idée des martyrs de la peste fit son chemin parmi les populations musulmanes ${ }^{130}$. On ne saurait voir dans cette disposition religieuse une terreur collective causée par la pandémie. Au contraire, la foi a converti une panique en conviction religieuse qui ne remplace pas les remèdes prophylactiques, mais les complète quand ils s'avèrent inefficaces.

Les épidémies furent aussi les occasions de multiplier les rassemblements religieux. Ce qui favorisa incontestablement leur propagation. Mais l'utilité attendue de ce genre de rassemblements restait purement spiri-

124. Mir. III, passim; MiChel le SyRIEN, Chronique, IX, 28, éd. Chabot, t. II, p. 240 (de Zacharie le rhéteur); Vie de saint Syméon Stylite le Jeune, c. 69-70. À Rome en 680, c'est saint Sébastien qui arrête la peste lorsqu'on dresse un autel en son honneur dans l'église de Saint-Pierre-aux-Liens et qu'on y insère ses reliques (Historia Longobardorum VI, 3).

125. Cf. Grégoire Palamas, Homélie 39, PG 151, 485-496.

126. IBN KHĀTIMA, Tahsīl..., f. 90. L'ennemi en question est la peste, dit-il.

127. IBN ABĪ haĞ̄̄LA, Daf an-niqma ..., f. 6.

128. Ibid., f. 56.

129. Ibid., f. 51-52.

130. En tout état de cause, les mentions écrites sont quasi absentes des manuscrits consultés. 
tuelle, d'où l'expression arabe qirā at al-latîf (lecture spirituelle d'apaisement) ${ }^{131}$ de tradition orale. C'est la formule répétée en cas de calamité. Ainsi, ibn Khātima, médecin résigné, abandonne le discours médical, en l'absence de remède contre la peste, surtout sous sa forme pneumonique. Son but est d'apporter un soutien moral aux fidèles de la grande mosquée d Almeria : «Face à la tragédie qui perturba le cours du jour et de la nuit, le seul devoir qui reste est celui de s'adresser à Dieu et de l'invoquer afin qu'Il repousse la calamité : le grand mal ne peut être repoussé que par le Grand Puissant ${ }^{132}$.

Pour mieux se justifier, il déclare: «Dans l'épidémie il y a un peu de la colère de Dieu Tout Puissant» ${ }^{33}$. Il rapporte une nouvelle fois ses propres faits et gestes : «J'ai opté dans ce sens dans mes paroles, pour les notables et pour la masse, les jours de mes allocutions à la grande mosquée d'Almeria. Que Dieu la garde tout au long de cette calamité, et après tous mes efforts, je n'ai trouvé pour leur repos et leur guérison que les vertus de Dieu le Très Puissant» ${ }^{134}$.

Le choc de l'épidémie, la panique et l'angoisse conduisirent les fidèles de toutes confessions, juifs, chrétiens ou musulmans, à recourir à des pratiques religieuses particulières. Car plus que tout, les pestiférés craignaient la mort solitaire et abandonnée, sans personne pour effectuer le travail du deuil nécessaire au repos de leur âme ${ }^{135}$. La chronique d'ibn abī Zar' (mort en 1326) reflète cet état d'esprit : «En l'année $571 / 1175$, il y eut une peste violente à Marrakech, les gens en mouraient sans être malades. Personne ne sortait sans inscrire son nom, son origine et son lieu de provenance sur un papier qu'il mettait dans sa poche; en cas de décès on le transportait chez lui, dans sa famille. Le nombre de morts a atteint à Marrakech le chiffre de 1700 personnes» ${ }^{136}$.

L'exemple suivant est du Machrek du $14^{e}$ siècle, durant la peste noire. La persistance de la maladie poussa tous les habitants de Damas à sortir dans les rues de la ville en procession. La scène est décrite par le voyageur venu du Maghreb ibn Battūta, qui fut le témoin oculaire de l'évolution de la maladie : «J'ai vu dans les jours de la grande peste à Damas à la fin du mois de rab $\overrightarrow{\mathbf{i}}$ second de l'année quarante-neuf (juillet 1348), un témoignage du respect des habitants de Damas pour cette mosquée... : le roi des émirs, lieutenant du sultan, Arghūn-Chāh, ordonna à un crieur de proclamer dans Damas que tout le monde eût à jeûner pendant trois jours et que personne ne fît cuire dans les marchés rien de ce qui sert à la nourriture de l'homme tout le long du jour (or, à Damas, la plupart des habi-

131. M. Melhaoui, Processions en Islam occidental médiéval au temps de la calamité : sécheresse et peste, Sources, Travaux Historiques 51-52, 1997, p. 110.

132. IBN KHĀTIMA, Tahsīl..., f. 85b.

133. Ibid., f. $84 \mathrm{~b}$.

134. Ibid., f. 85 b.

135. J. CHIFFOLEAU, La mort, la peste et l'au-delà, L'Histoire 174, février 1994, p. 8.

136. IBN ABĪ ZAR', Al-an̄is al-mutrib bi-rawd al-gartās (La fable mélodieuse du jardin des feuillets), Rabat 1973, p. 398. 
tants ne mangent que ce qu'on prépare dans les marchés). Les Damasquins jeûnèrent trois jours consécutifs, dont le dernier était un jeudi. Ensuite les émirs, les chérifs, les kadhîs et les autres ordres se réunirent tous pêle-mêle dans cette mosquée principale, au point qu'elle fut comble. Ils y passèrent la nuit du jeudi au vendredi, en priant, louant Dieu, et faisant des vœux. Ils firent après cela la prière de l'aurore, et tous sortirent à pied, tenant dans leurs mains le Coran et les émirs étaient nu-pieds. Tous les habitants de la ville, hommes, femmes, petits et grands prirent part à cette procession. Les juifs sortirent avec leur Pentateuque et les chrétiens avec leur Évangile, et ils étaient suivis de leurs femmes et de leurs enfants. Tous pleuraient, suppliaient et cherchaient un recours près de Dieu, au moyen de ses livres et de ses Prophètes. Ils se rendirent à la mosquée Elakdām, et ils y restèrent, occupés à supplier et à invoquer Dieu, jusque vers le Zaouāl (de midi à trois heures). Ensuite, ils retournèrent à la ville, ils firent la prière du vendredi et Dieu les soulagea» ${ }^{137}$.

Ce texte montre la mobilisation d'une société, toutes confessions confondues, touchée par la brutalité de l'épidémie. La marche est réservée habituellement à la calamité de la sécheresse; son but cette fois sera de repousser la peste ${ }^{138}$. De même dans l'Occident chrétien, le pape Grégoire préconisa une procession et une messe lors de la peste qui s'abattit sur Rome en l'an $590^{139}$, et Clément VI institua une messe particulière pour demander au Ciel la cessation de ce fléau, qui était encore en vigueur au début du $20^{\mathrm{e}} \mathrm{s.}^{140}$.

Ces comparaisons nous semblent utiles pour saisir la portée spirituelle de ces remèdes au temps de la pandémie. Les croyants de toutes les religions monothéistes firent alors appel à leurs valeurs communes, partagées par tous les esprits, même les plus rationnels. Ibn Khātima ne cesse de dire qu'il faut prier pour éloigner la maladie, sans se décourager. Il cite le verset 43 de la sourate al-An'ām (Les bestiaux) : «Pourquoi donc, lorsque notre rigueur leur vint, n'ont-ils pas imploré (la miséricorde $)^{141}$ ?». Le Prophète, qui priait pour les malades, les handicapés ou les invalides, était l'exemple à suivre pour le médecin imam.

\section{Convergences et divergences}

Au terme de cette étude comparative, on ne peut qu'être frappé des nombreuses convergences entre l'appréhension de la peste par les com-

137. IbN BATtuTa, Voyages, éd. et trad. C. Deferemery et B.R. SANGuinetTi, préface de S. Yerasimos, Paris 1990, t. I, p. 234-235.

138. M. MElhaOUI, Processions..., p. 105-113.

139. Docteur H.-H. MollareT et J. BROSSOLET, La procession de saint Grégoire et la peste à Rome en l'an 590, Médecine de France 199, 1969, p. 13-22.

140. J. VIARD, La messe pour la peste, Revue d'érudition de la Bibliothèque de l'École des chartes 61,1900, p. 336.

141. Le Saint Coran, p. 132. 
munautés byzantine et musulmane. Si, comme le dit Paul Veyne, la démarche de l'historien est de faire «l'inventaire des différences» ${ }^{142}$, cet inventaire ne peut se faire qu'une fois inventoriées les convergences.

\section{Convergences}

Face à un fléau qui touche indifféremment les populations quelles que soient leur culture et leur conviction religieuse, les deux traditions connaissent deux types de réaction. Un premier courant court-circuite les médiations naturelles et lit la peste comme un événement directement religieux. Ce courant combine la permanence d'une conception archaïque du sacré (pour qui la maladie est provoquée par la colère divine contre une transgression rituelle ou morale) et une interprétation immédiate, «fondamentaliste» dirions-nous aujourd'hui, des textes saints et en particulier de la Bible mais aussi du Coran ou de certains hadiths. Cette réaction peut avoir des conséquences négatives (expulsion des juifs de Sparte, explosions de superstition, culpabilisation des populations) ou positives dans certains cas (conversion des mœurs, en particulier vers une plus grande charité envers le prochain ou les malades).

Un second courant, issu de la tradition médicale grecque reprise par le monde arabe, cherche à discerner la part des causes secondes, sans cependant nier la souveraineté de la cause première qui est en Dieu. Ce second courant se trouve en butte à l'hostilité du premier, qui voit dans ce souci de la rationalité profane une entreprise impie, comme le montrent l'attitude de Théodore Agallianos, au $15^{\mathrm{e}} \mathrm{s}$., contre les partisans d'Anastase le Sinaïte, ou les résistances des théologiens intransigeants aux efforts d'ibn al-Khatīb pour établir la contagion.

Cette distinction ne doit cependant pas être trop tranchée, car beaucoup d'auteurs se situent à mi-chemin entre les deux courants : ainsi Dèmètrios Kydonès, qui voit dans la peste l'expression d'une colère de Dieu, ne peut pas être sans autre analyse rangé dans la catégorie des antirationalistes, lui qui fut l'un des premiers traducteurs grecs de Thomas d'Aquin. Quant à Anastase le Sinaïte, tenu pour le porte-parole des rationalistes, il n'exclut pas le fait que parfois seule une intervention divine peut expliquer la survenue d'un fléau. De même, tous les médecins musulmans préconisent la prière et la confiance en Dieu quand les autres remèdes ont échoué. En tout état de cause, le recours à des causalités rationnelles n'implique qu'exceptionnellement une contestation de la théologie traditionnelle.

\section{Divergences}

À côté de ces convergences, on peut discerner quelques divergences dans l'appréhension de la peste par les Byzantins et les musulmans.

142. P. VEYNE, L'inventaire des différences, Paris 1976. 
Une première divergence relève de la spécificité de la médecine arabe. Alors que les textes médicaux byzantins s'en tiennent généralement aux descriptions et explications des médecins antiques (qui refusaient la théorie de la contagion), les médecins arabes s'attachent davantage à tirer les leçons de l'observation. Durant la peste noire, les médecins andalous consignèrent un grand nombre d'observations qui permirent une plus grande prise en compte de la contagion. C'est sans doute par le truchement des médecins arabes que les médecins byzantins commencèrent à tenir compte eux aussi de ce facteur.

On peut aussi rechercher des divergences de nature théologique. En effet, les deux traditions n'ont pas la même conception des relations entre la liberté humaine et la souveraineté divine. C'est d'ailleurs un des thèmes de la polémique des chrétiens byzantins contre l'islam, comme le montre la Controverse entre un musulman et un chrétien de Jean Damascène $e^{143}$, qui débute par cette question du musulman au chrétien : «Qui, selon toi, est l'auteur du bien et du mal ?» À quoi le chrétien répond: «Nous disons que Dieu seul est l'auteur de tous les biens, mais Il ne l'est pas du mal». La question est centrale s'agissant de la peste : la réflexion des théologiens byzantins sur la peste s'enracine dans le traité de Basile Que Dieu n'est pas l'auteur des maux. Pour eux, le mal vient d'un mauvais usage de la liberté. À cette liberté, ils opposent le fatalisme des musulmans : si Dieu est l'auteur de tout ce qui existe, le mal comme le bien, c'est lui qui envoie la peste et il n'y a rien à faire pour y échapper. Mais peut-être n'y a-t-il là que querelle de mots, car si la théologie musulmane fait bien de Dieu la source ultime de tout ce qui advient, l'interprétation de la peste non comme un châtiment mais comme une miséricorde peut conduire à voir dans ce «fatalisme» une forme extrême de la confiance que préconisent aussi les Byzantins.

Les divergences ne doivent donc pas être majorées. Le christianisme byzantin connaît des réactions fatalistes, et l'islam des réflexions rationnelles sur la causalité des pestes. Surtout, la différence se situe souvent, non entre les deux traditions religieuses, mais à l'intérieur de chaque tradition, entre les réactions populaires et les réflexions des lettrés, comme entre les lettrés eux-mêmes. Enfin, toute l'affaire est piégée à partir du moment où la peste constitue un fléau sur lequel le savoir médical de l'époque, aussi rationnel fût-il, n'avait aucune prise. Il était donc difficile pour les savants de prouver leurs assertions (puisque la médecine demeurait impuissante), et la spiritualité restait souvent le seul recours efficace face à un phénomène que nul ne pouvait maîtriser, mais qu'on pouvait essayer de vivre le moins mal possible.

Marie-Hélène Congourdeau (CNRS, UMR 7572)

Mohammed Melhaou (Docteur en histoire)

143. Cf. JEAN DAMASCÈNE, Controverse entre un musulman et un chrétien, SC 383. 